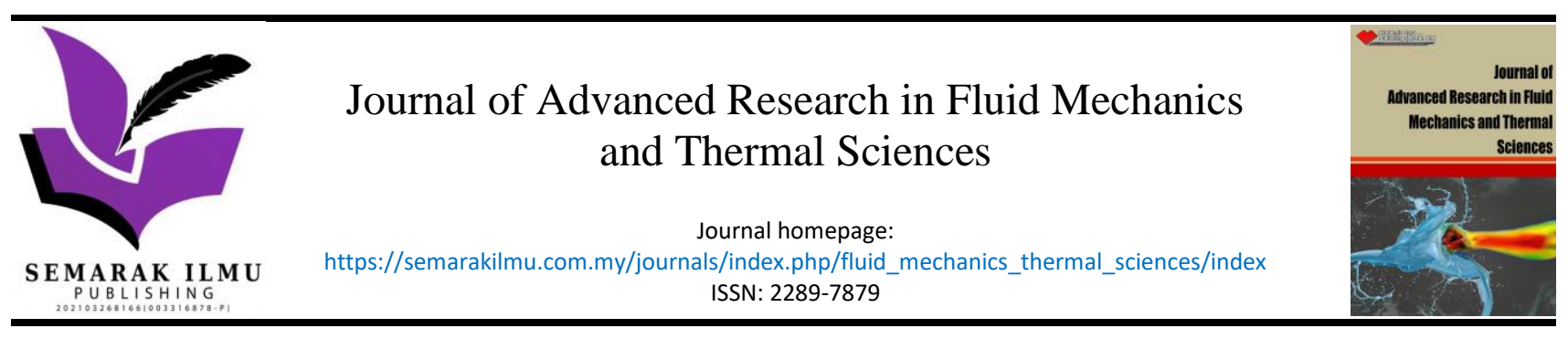

\title{
The Removal of Biomass Tar Derived Producer Gas by Means of Thermal and Catalytic Cracking Methods
}

\author{
Hafnee Lateh ${ }^{1}$, Juntakan Taweekun ${ }^{1,},{ }^{*}$ Kittinan Maliwan ${ }^{1}$, Zainal Alimuddin Zainal Alauddin², \\ Sukritthira Rattanawilai ${ }^{3}$

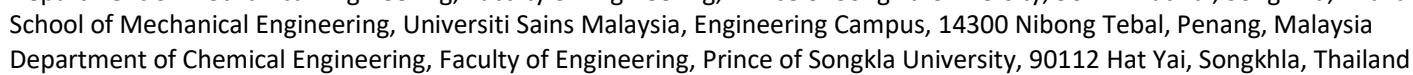

\section{ARTICLE INFO
ABSTRACT}

\section{Article history:}

Received 2 June 2021

Received in revised form 20 September 2021

Accepted 25 September 2021

Available online 31 October 2021

\section{Keywords:}

Thermal and catalytic cracking; modified catalyst; biomass gasification; biomass tar

\begin{abstract}
Tar derived from biomass gasification system needs to be eliminated before applying biomass producer gas for avoiding equipment and its gas problems. In this study, thermal and catalytic cracking methods of biomass tar along with microwave assistance in heat transfer were experimented at various temperatures during 650$1,200{ }^{\circ} \mathrm{C}$ and residence at $0.24-0.5 \mathrm{~s}$. The results present that high tar removal efficiency by approximately $90 \%$ under thermal cracking treatment and about $98 \%$ with catalytic cracking method. It also shows that the catalytic cracking especially modified catalyst could be lowered carbon deposition on catalyst surface.
\end{abstract}

\section{Introduction}

The lack of fossil fuel energy and the environmental impacts due to the abundant usability of fossil fuel energy, those issues have caused the renewable energy source is considered for substitution of its energy [1]. Among of renewable energy, biomass energy source is the most interesting because of its advantages and low pollutant emission. Gasification, the one commonly used of thermochemical technology, transforms biomass source into useful energy such as biomass producer gas. That gas is mainly composed of $\mathrm{H}_{2}, \mathrm{CO}, \mathrm{CO}_{2}, \mathrm{CH}_{4}$ and also some dirty products such as tar and particles [2-4]. Tar is a main point in biomass gasification system because it can be a lot of problems to all equipment and producer gas too $[5,6]$. The tar along with producer gas is imperative to decompose for avoiding from tar problems before using in any applications [7]. The removal of tar can be divided into three approaches: 1) mechanical or physical method, 2) thermal treatment method and 3) catalytic cracking method $[3,7,8]$. Nevertheless, thermocatalytic treatment method, thermal and/or catalytic cracking, is desirable because its treatment can remove the tar and convert

\footnotetext{
* Corresponding author.

E-mail address: jantakan.t@psu.ac.th

https://doi.org/10.37934/arfmts.88.2.147156
} 
into advantageous gases such as $\mathrm{H}_{2}, \mathrm{CO}$ or $\mathrm{HCN}$ gases which can improve energy content of syngas [9].

It has been reported that the heavy tar can be cracked by using thermal cracking at temperature of $900{ }^{\circ} \mathrm{C}$ [10]. Meanwhile, the high temperature upper than $1,100{ }^{\circ} \mathrm{C}$ is sufficiently required to complete the tar removal [11]. It is also mentioned that thermal cracking method has been shown high tar removal efficiency with operating at temperature of $1,200{ }^{\circ} \mathrm{C}$ and residence time shorter than $10 \mathrm{~s}$. Zhang et al., [12] have mentioned that one of biomass tar composition (toluene) was hardly to remove, and should be up the temperature to $1,200^{\circ} \mathrm{C}$ for elimination. In term of catalytic cracking method, this method is extremely favorable because tar can be removed and reformed into gaseous compositions with increasing quantity of $\mathrm{H}_{2}$ and $\mathrm{CO}$ on producer gas $[8,13]$. Several types of catalysts have been tested on tar removal such as nickel based, non-nickel metal, alkali metal, basic, acid, and activated carbon $[3,13]$. Among of these catalysts, nickel-supported catalysts are the most used catalyst for tar decomposition. They present not only high activity on tar removal but also increasing $\mathrm{H}_{2}$ and $\mathrm{CO}$ contents of the producer gas and low-price costs [14]. It has suggested that Ni-based catalysts supported by alumina $\left(\mathrm{Al}_{2} \mathrm{O}_{3}\right)$ as metal oxides, or dolomite, olivine as natural materials are considered to have a positive effect in transforming tar into useable gas [15]. Nickel alumina, $\mathrm{Ni} / \mathrm{Al}_{2} \mathrm{O}_{3}$ catalyst, presents high catalytic activity and tar removal efficiency but it is not stable and eventual deactivation $[14,16]$. Several parameters such as acidity, pore, structure, and surface area of the support are determined of catalytic activity [17]. Anis and Zainal [3] have reported that nickel-based catalysts can be completely eliminated the tar at temperature of $900^{\circ} \mathrm{C}$, depending on promoter and support used types. In spite of the high activity of nickel-based catalysts, the main disadvantages with these catalysts have been occurred as rapid deactivation because of carbon deposition on catalyst surface (coke formation) and catalyst reduction. Furthermore, the other issue of thermal and catalytic cracking treatment of tar method is the high energy demand to complete tar removal at temperature range of $700-1,200^{\circ} \mathrm{C}$. It has been reported that treatment usually uses an external high electrical source where heat transfer arises from the surface into the core of material. Some effects such as heat transfer resistance, heat losses to surrounding and the corrosion of wall reactor are the lack of this treatment because of the continued high electrical heating [18].

This paper, the activity of thermocatalytic treatment of biomass tar was investigated. In addition, in order that the effectiveness of tar removal during it treatment, the modified catalyst and the microwave assisted were tested by using biomass tar derived from producer gas with various temperature conditions.

\section{Methods}

\subsection{Catalyst Preparation}

The $\mathrm{Al}_{2} \mathrm{O}_{3}$ catalyst as commercial grade, was prepared through wetness impregnation method as followed with Liu et al., [19]. Starting with the catalyst was dried in an oven at temperature of $120^{\circ} \mathrm{C}$ overnight for removal catalyst moister along with immersion of dry catalyst into magnesium nitrate solution at room temperature for $24 \mathrm{~h}$. The catalyst was calcined in a furnace at temperature of 500 ${ }^{\circ} \mathrm{C}$ about $3 \mathrm{~h}$ and then cooling the catalyst at ambient temperature. Finally, the $\mathrm{Mg} / \mathrm{Al}_{2} \mathrm{O}_{3}$ catalyst was immersed again into nickel nitrate solution and following same previous process.

\subsection{Materials}

The commercial wood pellets were used as biomass fuels for producer gas production in a downdraft gasifier. The properties of wood pellet are listed in Table 1. 
Table 1

Properties of wood pellets

\begin{tabular}{ll}
\hline Proximate analysis (wt \% dry basis) & \\
\hline Fixed carbon & 14.8 \\
Volatile matter & 76.2 \\
Ash & 0.5 \\
Moisture & 9 \\
Elemental analysis (wt \% dry ash-free basis) & \\
Carbon & 44.55 \\
Hydrogen & 7.54 \\
Nitrogen & 0.06 \\
Sulfur & 0.17 \\
Oxygen & 47.67 \\
HHV (MJ/kg) & 17.8 \\
\hline
\end{tabular}

\subsection{Experimental Apparatus and Parameters}

The schematic diagram of the overall experimental apparatus system is shown in Figure 1 . The system was consisted of three subsystems: a) biomass gasifier, b) tar cracking unit, and c) tar sample collection.

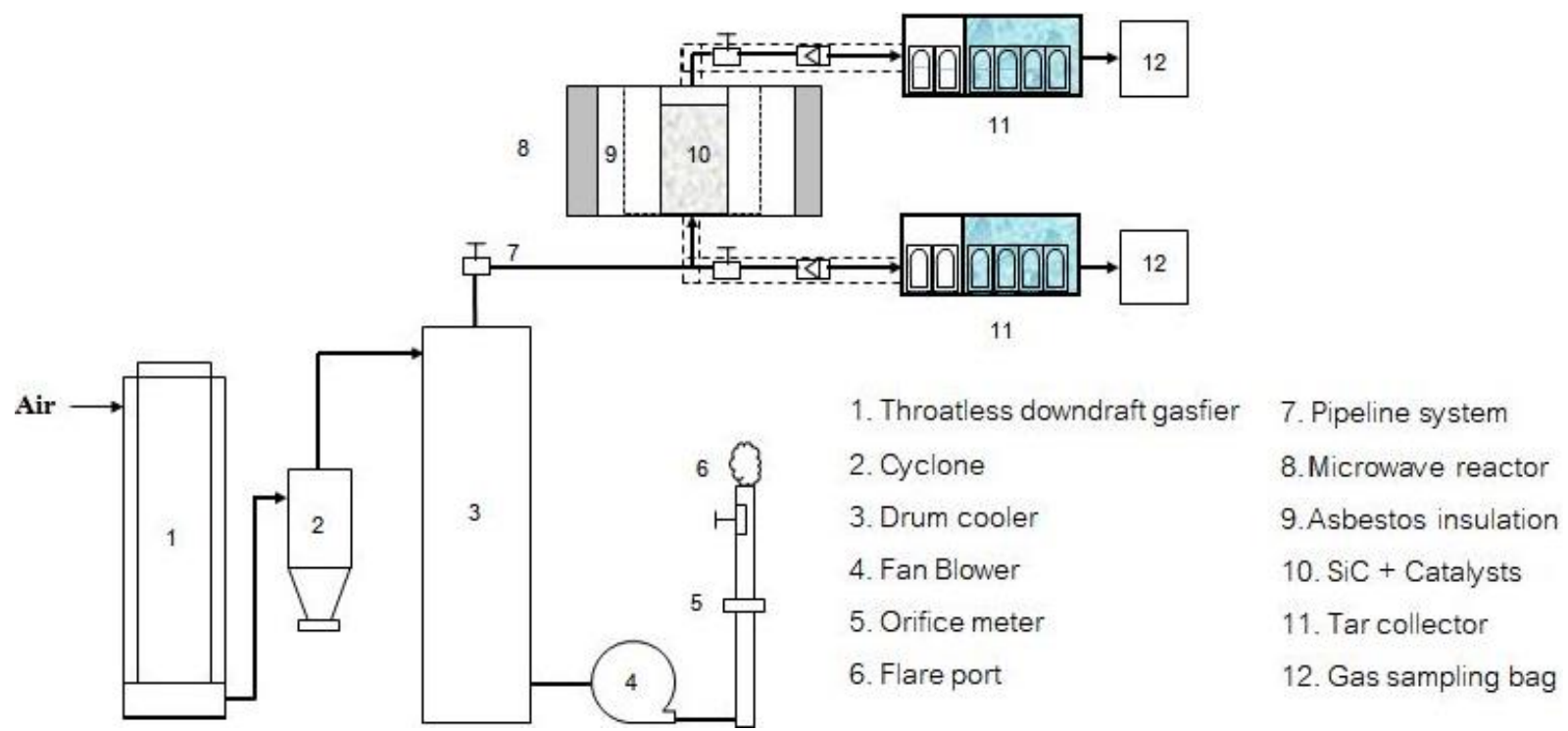

Fig. 1. The schematic diagram of thermocatalytic cracking of biomass tar

The biomass gasifier system was composted of a throatless downdraft fixed bed, cyclone, drum cooler, blower, and gas flare. The gasifier has a thermal power output of $8.3 \mathrm{~kW}$ which depends on biomass feeding rate of $5 \mathrm{~kg} / \mathrm{h}$.

Tar cracking system was consisted a modified microwave and alumina reactor. A microwave oven was drilled the hole for installing alumina tube reactor with a height of $16 \mathrm{~cm}, 2.54 \mathrm{~cm}$ of internal diameter and $0.5 \mathrm{~cm}$ of thickness inside microwave chamber. It provides 700 and 1,125 W of maximum microwave power output and power consumption, respectively. Silicon carbide (SiC), susceptor material, was used for absorption and conversion the energy of microwave into heat. In addition, a temperature controller was attached into the system to control and maintain the temperature within reactor.

The tar sample collection system included a tar sampling train, vacuum pump, and flow meter. A tar sampling train has been modified to capture tar and particles in producer gas with six impinger 
bottles [20]. Each bottle was filled with $50 \mathrm{ml}$ of isopropanol other than the last bottle was empty. The first two bottles were placed at ambient temperature and next four bottles were submerged into an ice box. That ice box was filled with the mixture of ice and salt together for keeping temperature about $-22{ }^{\circ} \mathrm{C}$ which suffices to condense the tar [21]. The dry producer gas was suctioned and flowed through the tar removal and this system by using a vacuum pump. A flow meter was installed in this system for measuring and controlling the flow rate of biomass producer gas.

Table 2 presents the experimental parameters for thermocatalytic cracking of biomass tar. The temperatures were tested in the range of $700-1,200{ }^{\circ} \mathrm{C}$. The residence time was set at $0.24-0.5 \mathrm{~s}$ depending on gas flow rate of 3.8-5 LPM.

\begin{tabular}{lll}
$\begin{array}{l}\text { Table } 2 \\
\begin{array}{l}\text { The } \\
\text { thermocatalytic cracking of biomass tar }\end{array}\end{array}$ & \\
thermental & \multicolumn{1}{c}{ forameters } \\
\hline Condition & Parameter & Unit \\
\hline Catalyst mass & 3 & $\mathrm{~g}$ \\
Biomass producer gas flow rate & $3.8-5$ & $\mathrm{LPM}$ \\
Catalyst bed height & 3 & $\mathrm{~cm}$ \\
Residence time & $0.24-0.5$ & $\mathrm{~s}$ \\
Temperature & $700-1,200$ & ${ }^{\circ} \mathrm{C}$ \\
Microwave power & 0.7 & $\mathrm{~kW}$ \\
\hline
\end{tabular}

\subsection{Thermocatalytic}

This study was focused on biomass tar removal through thermal and catalytic cracking methods. The biomass producer gas was run through the pipeline system from downdraft gasifier until the tar sample collection system. In term of thermal cracking method, the range of testing temperature was operated during $900-1,200{ }^{\circ} \mathrm{C}$ with residence time of $0.5 \mathrm{~s}$. For catalytic cracking method, the catalysts and absorber material, $\mathrm{SiC}, \mathrm{SiC}+$ catalysts and $\mathrm{SiC}$, were arranged into three layers with total of bed high $120 \mathrm{~cm}$ inside the reactor. Each experimental was set $3 \mathrm{~g}$ of $\mathrm{Ni} / \mathrm{Mg} / \mathrm{Al}_{2} \mathrm{O}_{3}$ and mixed together with $\mathrm{SiC}$ about $25 \mathrm{~g}$. The temperature was tested in the range of $700-900{ }^{\circ} \mathrm{C}$ with residence time of $0.24 \mathrm{~s}$.

\subsection{Sampling and Analysis}

The biomass producer gas, before and after exit the microwave reactor, was flowed through sample collection system. The biomass tar samples were captured in the isopropanol solution in tar collection system and then were filtered through a Whatman filter paper to separate particles. The filtered solution of isopropanol with the condensed tar was sent into BUCHI rotary evaporator to evaporate and determine the gravimetric of tar. The gas after cracking was sent into the gas sampling bag and then investigated with GC-TCD to analyze the quantification gas composition. Thethermogravimetric analyser or TGA was used to determine the carbon deposited on catalyst.

\section{Result and Discussion}

\subsection{The Biomass Gasification}

As the process of thermochemical derived biomass gasification, the producer gas which was produced by a throatless downdraft gasifier of wood pellet in this study contains not only useful gas 
such as hydrogen, nitrogen, oxygen, methane and carbon dioxide but also tar, water and particulates [22]. Table 3 shows the products of producer gas as well as some related data.

Table 3

The products of producer gas from a throatless downdraft gasifier

\begin{tabular}{lll}
\hline Parameter & $\begin{array}{l}\text { Value } \\
\text { Thermal cracking method }\end{array}$ & Catalytic cracking method \\
\hline Gasifier condition & & \\
Equivalence ratio (ER) & 0.26 & 0.26 \\
Low heating value (LHV) & $4.44 \mathrm{MJ} / \mathrm{Nm}^{3}$ & $4.32 \mathrm{MJ} / \mathrm{Nm}^{3}$ \\
Products yields at sample point & wt.\% & wt.\% \\
Gas & 94.55 & 92.96 \\
Tar & 0.23 & 0.34 \\
Water & 5.14 & 6.65 \\
Particulates & 0.07 & 0.05 \\
The composition of producer gas & vol.\% & vol.\% \\
Hydrogen & 10.7 & 10.23 \\
Oxygen & 3.27 & 3.14 \\
Carbon monoxide & 19.86 & 19.5 \\
Methane & 2.18 & 2.12 \\
Carbon dioxide & 10.45 & 10.25 \\
Nitrogen & 53.56 & 54.76 \\
\hline
\end{tabular}

\subsection{Thermal Cracking of Biomass Tar}

Thermal cracking of biomass tar from wood pellet gasification was tested on temperature during 900-1200 ${ }^{\circ} \mathrm{C}$. The composition of producer gas and low heating value (LHV) presents in Figure 2. At $900{ }^{\circ} \mathrm{C}, \mathrm{H}_{2}$ and $\mathrm{O}_{2}$ appear slightly decrease from initial of raw producer gas. The result of $\mathrm{CO}$ shows increase as the temperature of testing goes up that because of the forming from partial oxidation of solid particles as reported by Anis and Zainal [9].

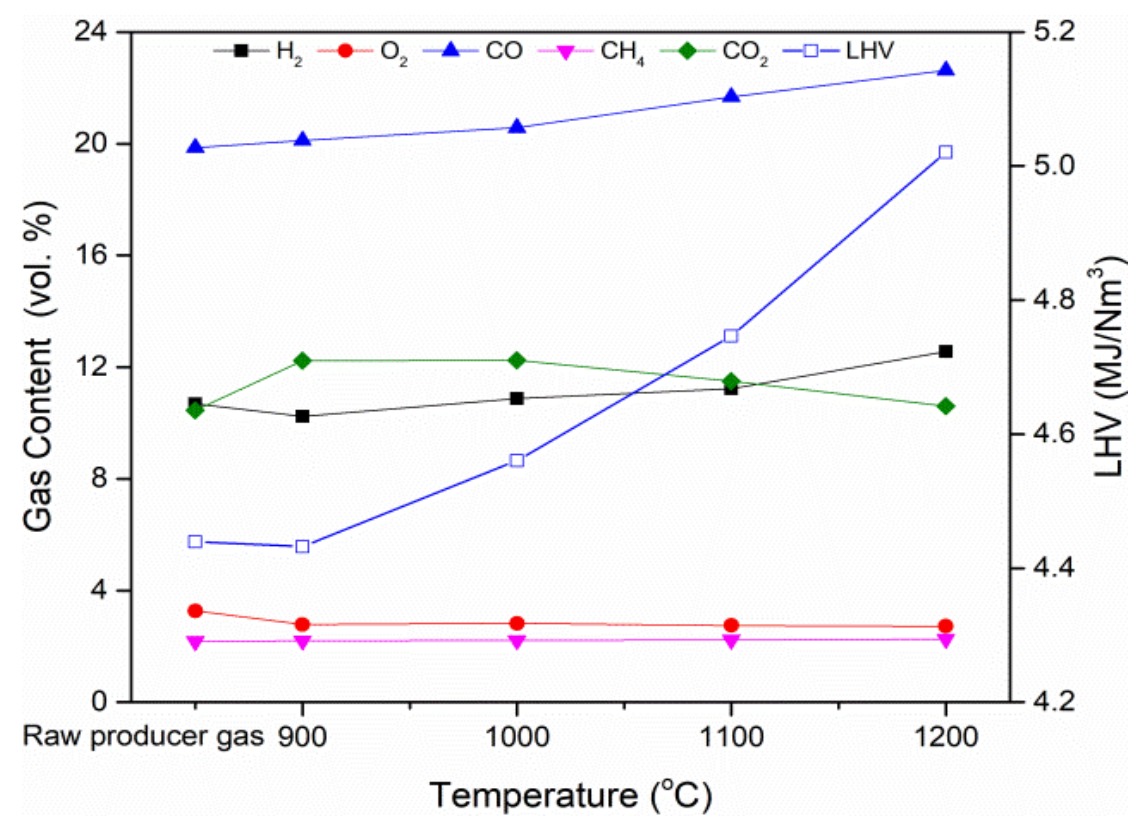

Fig. 2. Gas formation and LHV by thermal cracking of biomass tar 
The results in Figure 2 also present difference effects of gas composition when the gas formations come to be intenseness of flammable gases at high temperature. The partial oxidation, water gas reaction, and Boudouard reaction are created the flammable gases by supporting of $\mathrm{O}_{2}$, water, and particle. By the time of increasing the temperature of reaction, $\mathrm{CO}$ and $\mathrm{H}_{2}$ products show increase formation but $\mathrm{CH}_{4}$ and $\mathrm{CO}_{2}$ appear decreasingly. The yield of products both tar and particle perform inverse variation with testing temperature as shown in Figure 3 . At the maximum reaction temperature, the tar and particle are decomposed more than $90 \%$ and $97 \%$ with final concentration of them about $0.182 \mathrm{~g} / \mathrm{Nm}^{3}$ and $0.015 \mathrm{~g} / \mathrm{Nm}^{3}$, respectively. These results confirm to mention of Zhang et al., [12] as the removal accomplishment of tar and particle derived from producer gas by thermal treatment occurs at high temperature above $1,200^{\circ} \mathrm{C}$.

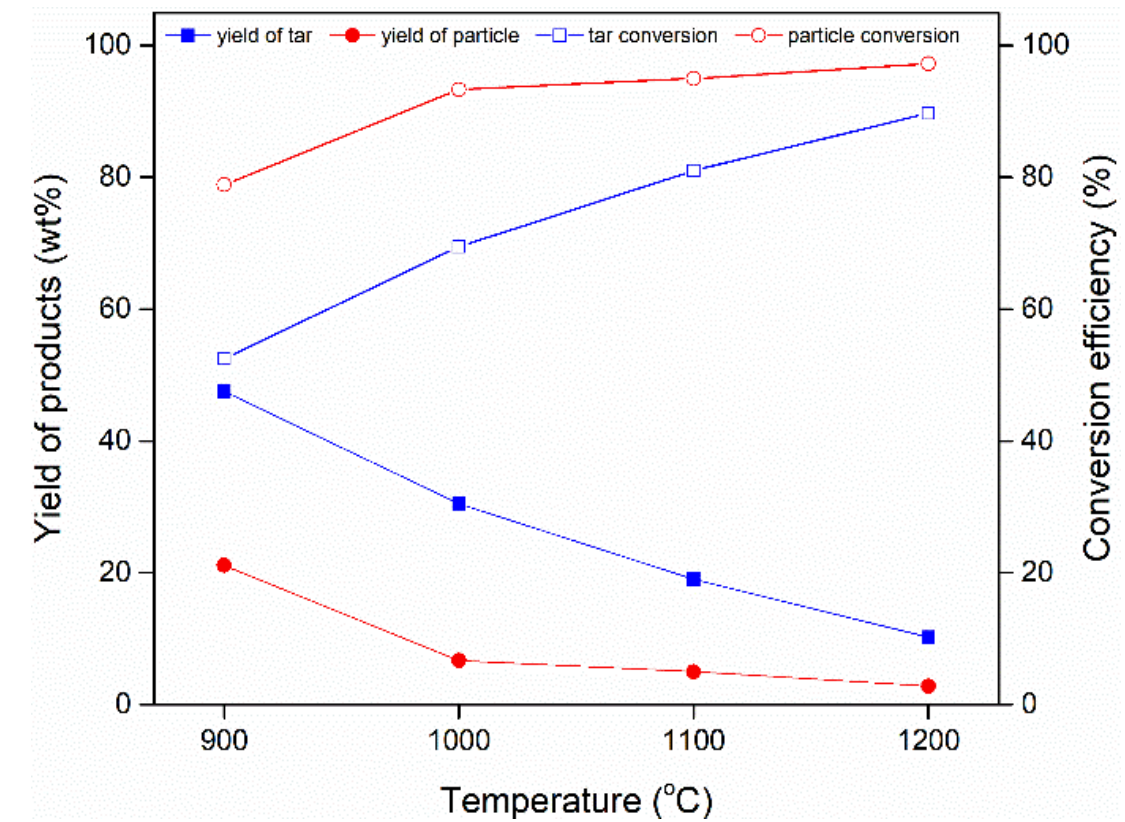

Fig. 3. Yield of products and product conversion efficiency by thermal cracking of biomass tar

\subsection{Catalytic Cracking of Biomass Tar}

Catalytic cracking of biomass tar from wood pellet gasification was run under temperatures during $700-900{ }^{\circ} \mathrm{C}$. The gas composition of producer gas and LHV are presented in Figure 4 . The yield of products along with product conversion efficiency by $\mathrm{Ni} / \mathrm{Mg} / \mathrm{Al}_{2} \mathrm{O}_{3}$ cracking of biomass tar display in Figure 5.

At $700{ }^{\circ} \mathrm{C}, \mathrm{H}_{2}$ and $\mathrm{CO}$ seem slightly decrease whilst $\mathrm{CH}_{4}$ and $\mathrm{CO}_{2}$ show opposite curve from initial value of raw producer gas. In this temperature reaction, the concentration of tar is reduced from initial of $\operatorname{tar}$ (raw producer gas) at $2.63 \mathrm{~g} / \mathrm{Nm}^{3}$ to $0.58 \mathrm{~g} / \mathrm{Nm}^{3}$. The tar and particle are converted about $82 \%$ and $88 \%$, respectively. The graph in Figure 4 also displays the gas content of $\mathrm{CO}_{2}$ and $\mathrm{CH}_{4}$ which are imperceptible difference at reaction temperature of $800^{\circ} \mathrm{C}$. While, $\mathrm{CO}$ shows to increase the gas content from initial of raw producer gas until $900^{\circ} \mathrm{C}$. That result is because the Boudourd reaction as following in Eq. (1) with occurrence at high temperature [23]. At higher temperature of $800{ }^{\circ} \mathrm{C}, \mathrm{CH}_{4}$ exits increase formation that because the reforming products such as $\mathrm{H}_{2}, \mathrm{O}_{2}$, and $\mathrm{CO}_{2}$ prevent reaction of methane steam reforming on catalyst as Eq. (2) [23]. 


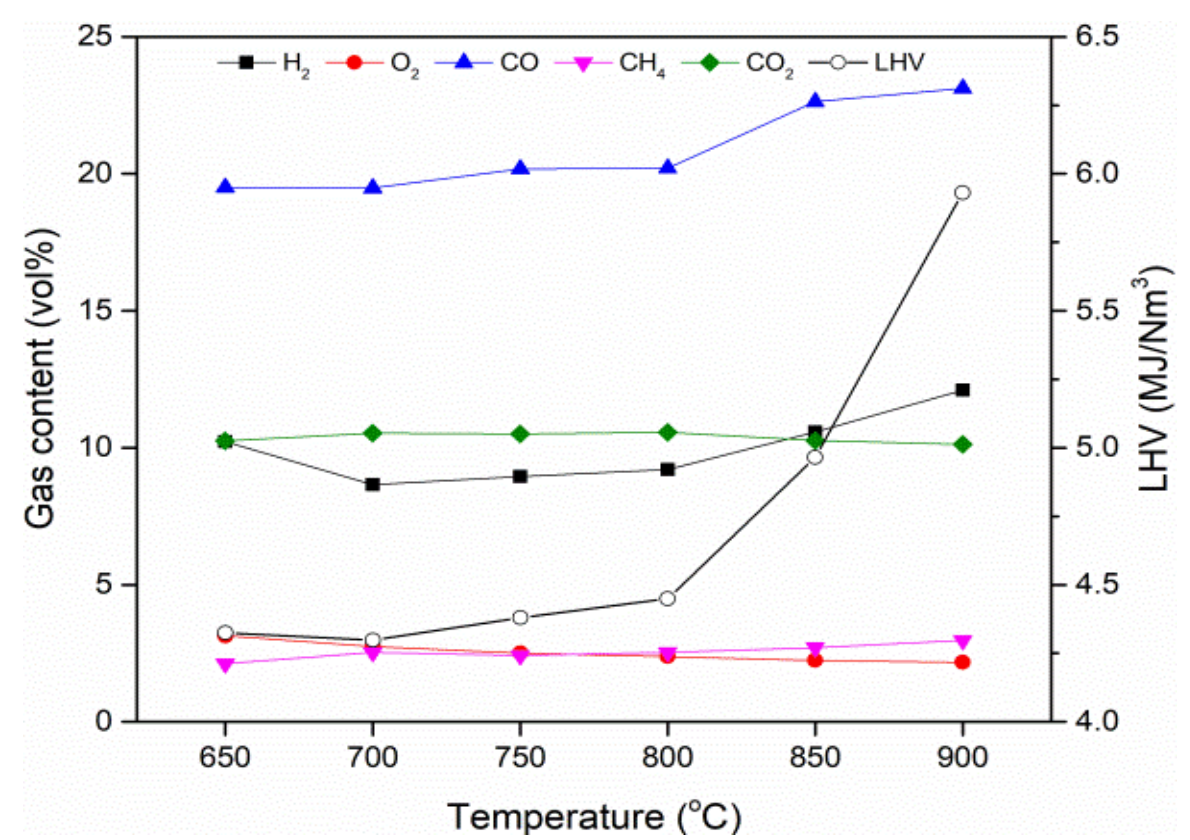

Fig. 4. Gas formation and $\mathrm{LHV}$ by $\mathrm{Ni} / \mathrm{Mg} / \mathrm{Al}_{2} \mathrm{O}_{3}$ cracking of biomass tar

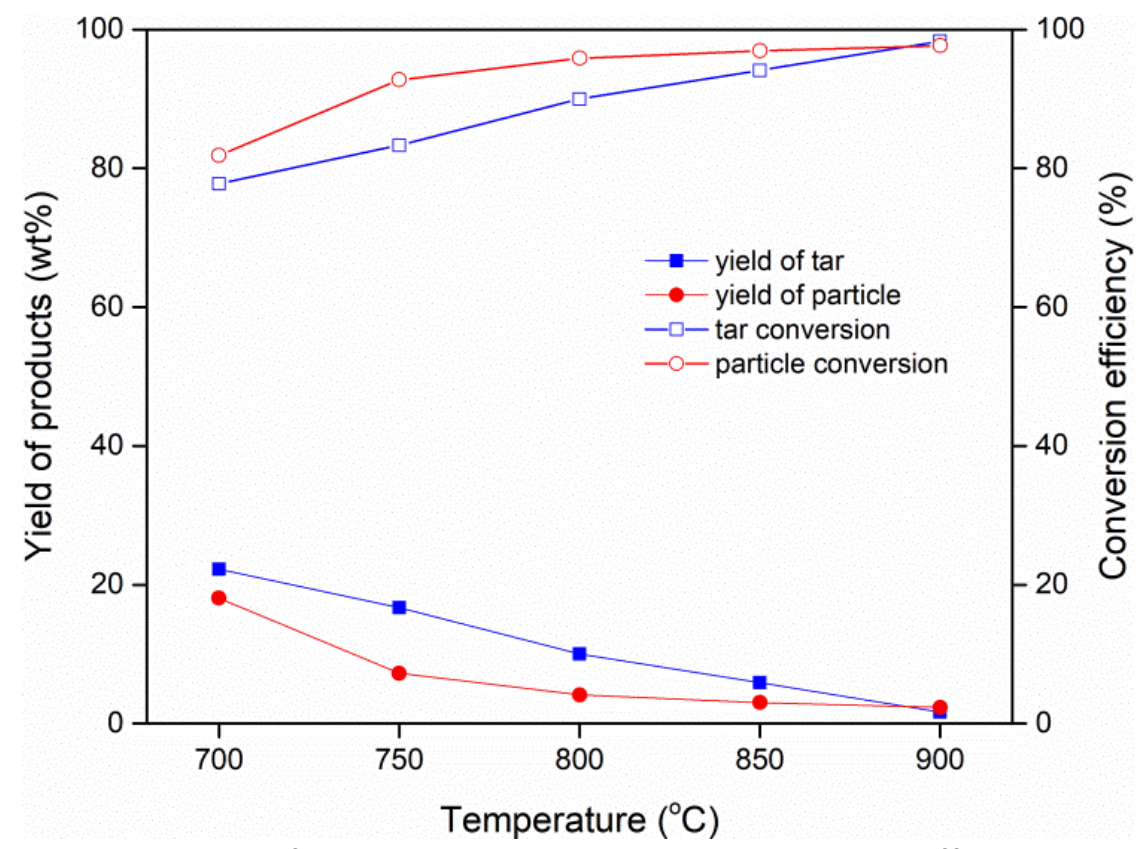

Fig. 5. Yield of products and product conversion efficiency by $\mathrm{Ni} / \mathrm{Mg} / \mathrm{Al}_{2} \mathrm{O}_{3}$ cracking of biomass tar

$\mathrm{C}+\mathrm{CO}_{2} \leftrightarrow 2 \mathrm{CO}$

$\mathrm{CH}_{4}+\mathrm{H}_{2} \mathrm{O} \rightarrow \mathrm{CO}+3 \mathrm{H}_{2}$

As shown in Figure 5, at temperature of $900{ }^{\circ} \mathrm{C}$, the highest tar is cracked by $\mathrm{Ni} / \mathrm{Mg} / \mathrm{Al}_{2} \mathrm{O}_{3}$ about $98 \%$ that tar concentration remains $0.044 \mathrm{~g} / \mathrm{Nm}^{3}$ whereas the lowest of particle is about $0.009 \mathrm{~g} / \mathrm{Nm}^{3}$. The yield of coke deposition on catalyst surface as presented in Figure 6, it appears to be related to tar removal efficiency. It is the reduction of coke deposition with resulting in high tar removal as reported by some studies $[24,25]$. 


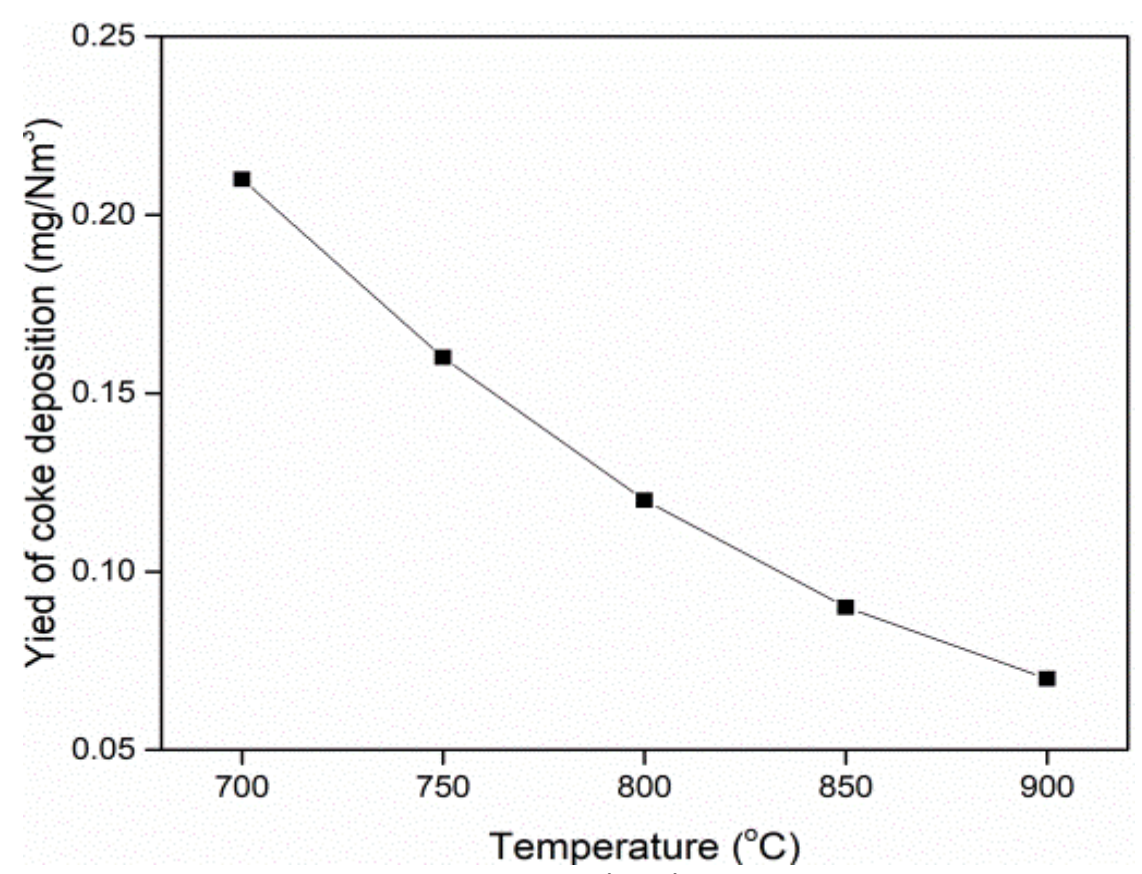

Fig. 6. Yield of coke deposition by $\mathrm{Ni} / \mathrm{Mg} / \mathrm{Al}_{2} \mathrm{O}_{3}$ cracking of biomass tar

\section{Conclusions}

The performance of thermal and catalytic cracking methods of biomass tar has been studied at several temperature tests during $700-1,200{ }^{\circ} \mathrm{C}$ and residence time of $0.24-0.5 \mathrm{~s}$. Wood pellets were used as biomass fuels for producer gas production of this study with $\mathrm{HHV}$ of $17.8 \mathrm{MJ} / \mathrm{Kg}$. In this paper, thermal cracking method shows high removal efficiency of tar at $1200{ }^{\circ} \mathrm{C}$ about $90 \%$ with tar concentration of $0.182 \mathrm{~g} / \mathrm{Nm}^{3}$. The achievement of tar removal by using $\mathrm{Ni} / \mathrm{Mg} / \mathrm{Al}_{2} \mathrm{O}_{3}$ is about $98 \%$ corresponds to the concentration remained $0.044 \mathrm{~g} / \mathrm{Nm}^{3}$ from initial tar concentration of $2.63 \mathrm{~g} / \mathrm{Nm}^{3}$. In addition, the effect of upgraded catalyst can be caused to removal high efficiency of biomass tar whereas that catalyst has occurred low carbon deposition on its surface.

\section{Acknowledgments}

The authors would like to thank The Department of Mechanical Engineering, Faculty of Engineering, Prince of Songkla University (PSU) and School of Mechanical Engineering, Universiti Sains Malaysia (USM), Engineering Campus, Malaysia for the laboratory facilities; The PSU Ph.D. scholarship grant from the Graduate School; The financial support through the Thailand government research grant no. ENG 600608S; and the Research Grants for Higher Education Student 2017 through the Energy Conservation Promotion Fund, Ministry of Energy.

\section{References}

[1] Savuto, E., R. M. Navarro, N. Mota, A. Di Carlo, E. Bocci, M. Carlini, and J. L. G. Fierro. "Steam reforming of tar model compounds over Ni/Mayenite catalysts: effect of Ce addition." Fuel 224 (2018): 676-686. https://doi.org/10.1016/i.fuel.2018.03.081

[2] Zhang, Zhikun, Lina Liu, Boxiong Shen, and Chunfei Wu. "Preparation, modification and development of Ni-based catalysts for catalytic reforming of tar produced from biomass gasification." Renewable and Sustainable Energy Reviews 94 (2018): 1086-1109. https://doi.org/10.1016/i.rser.2018.07.010

[3] Anis, Samsudin, and Z. A. Zainal. "Tar reduction in biomass producer gas via mechanical, catalytic and thermal methods: A review." Renewable and Sustainable Energy Reviews 15, no. 5 (2011): 2355-2377. https://doi.org/10.1016/i.rser.2011.02.018 
[4] Basu, Prabir. Biomass gasification, pyrolysis and torrefaction: practical design and theory. Academic Press, 2018. https://doi.org/10.1016/B978-0-12-812992-0.00007-8

[5] Liu, Haibo, Tianhu Chen, Xianlong Zhang, Jinhu Li, Dongyin Chang, and Lei Song. "Effect of additives on catalytic cracking of biomass gasification tar over a nickel-based catalyst." Chinese Journal of Catalysis 31, no. 4 (2010): 409414. https://doi.org/10.1016/S1872-2067(09)60061-9

[6] Abu El-Rub, Ziad, Eduard A. Bramer, and Gerrit Brem. "Review of catalysts for tar elimination in biomass gasification processes." Industrial \& Engineering Chemistry Research 43, no. 22 (2004): 6911-6919. https://doi.org/10.1021/ie0498403

[7] Milne, Thomas A., Robert J. Evans, and N. Abatzaglou. "Biomass gasifier"Tars": their nature, formation, and conversion." National Renewable Energy Laboratory, United States, 1998. https://doi.org/10.2172/3726

[8] Buchireddy, Prashanth Reddy, R. Mark Bricka, Jose Rodriguez, and William Holmes. "Biomass gasification: catalytic removal of tars over zeolites and nickel supported zeolites." Energy \& Fuels 24, no. 4 (2010): 2707-2715. https://doi.org/10.1021/ef901529d

[9] Anis, Samsudin, and Z. A. Zainal. "Upgrading producer gas quality from rubber wood gasification in a radio frequency tar thermocatalytic treatment reactor." Bioresource Technology 150 (2013): $328-337$. https://doi.org/10.1016/i.biortech.2013.10.010

[10] Qin, YuHong, HaiFeng Huang, ZhiBin Wu, Jie Feng, Wenying Li, and KeChang Xie. "Characterization of tar from sawdust gasified in the pressurized fluidized bed." Biomass and Bioenergy 31, no. 4 (2007): $243-249$. https://doi.org/10.1016/i.biombioe.2006.06.017

[11] Jess, Andreas. "Mechanisms and kinetics of thermal reactions of aromatic hydrocarbons from pyrolysis of solid fuels." Fuel 75, no. 12 (1996): 1441-1448. https://doi.org/10.1016/0016-2361(96)00136-6

[12] Zhang, Yan, Shiro Kajitani, Masami Ashizawa, and Yuso Oki. "Tar destruction and coke formation during rapid pyrolysis and gasification of biomass in a drop-tube furnace." Fuel 89, no. 2 (2010): 302-309. https://doi.org/10.1016/i.fuel.2009.08.045

[13] Wang, Duo, Wenqiao Yuan, and Wei Ji. "Char and char-supported nickel catalysts for secondary syngas cleanup and conditioning." Applied Energy 88, no. 5 (2011): 1656-1663. https://doi.org/10.1016/i.apenergy.2010.11.041

[14] Sutton, David, Brian Kelleher, Aidan Doyle, and J. R. H. Ross. "Investigation of nickel supported catalysts for the upgrading of brown peat derived gasification products." Bioresource Technology 80, no. 2 (2001): 111-116. https://doi.org/10.1016/S0960-8524(01)00086-4

[15] Pompeo, Francisco, Nora N. Nichio, Osmar A. Ferretti, and Daniel Resasco. "Study of Ni catalysts on different supports to obtain synthesis gas." International Journal of Hydrogen Energy 30, no. 13-14 (2005): 1399-1405. https://doi.org/10.1016/i.ijhydene.2004.10.004

[16] Srinakruang, Jumluck, Kazuhiro Sato, Tharapong Vitidsant, and Kaoru Fujimoto. "Highly efficient sulfur and coking resistance catalysts for tar gasification with steam." Fuel 85, no. 17-18 (2006): 2419-2426. https://doi.org/10.1016/i.fuel.2006.04.026

[17] Yung, Matthew M., Whitney S. Jablonski, and Kimberly A. Magrini-Bair. "Review of catalytic conditioning of biomass-derived syngas." Energy \& Fuels 23, no. 4 (2009): 1874-1887. https://doi.org/10.1021/ef800830n

[18] Salema, Arshad Adam, and Farid Nasir Ani. "Microwave induced pyrolysis of oil palm biomass." Bioresource Technology 102, no. 3 (2011): 3388-3395. https://doi.org/10.1016/j.biortech.2010.09.115

[19] Liu, Xue, Johannes G. Khinast, and Benjamin J. Glasser. "Drying of Ni/Alumina catalysts: control of the metal distribution using surfactants and the melt infiltration method." Industrial \& Engineering Chemistry Research 53, no. 14 (2014): 5792-5800. https://doi.org/10.1021/ie500099c

[20] Van Paasen, S. V. B., J. H. A. Kiel, J. P. A. Neeft, H. A. M. Knoef, G. J. Buffinga, U. Zielke, K. Sjostrom et al. “Guideline for sampling and analysis of tar and particles in biomass producer gases." Final Report Documenting the Guideline, R\& D Work and Dissemination, Netherlands 95 (2002).

[21] Bergman, P. CA, S. VB Van Paasen, and Harold Boerrigter. The novel'OLGA'technology for complete tar removal from biomass producer gas. CPL Press, Netherlands, 2002.

[22] Ahmad, Nor Azlina, and Z. A. Zainal. "Performance and chemical composition of waste palm cooking oil as scrubbing medium for tar removal from biomass producer gas." Journal of Natural Gas Science and Engineering 32 (2016): 256-261. https://doi.org/10.1016/i.jngse.2016.03.015

[23] Qian, Kezhen, and Ajay Kumar. "Catalytic reforming of toluene and naphthalene (model tar) by char supported nickel catalyst." Fuel 187 (2017): 128-136. https://doi.org/10.1016/i.fuel.2016.09.043

[24] Wang, Tiejun, Jie Chang, Xiaoqin Cui, Qi Zhang, and Yan Fu. "Reforming of raw fuel gas from biomass gasification to syngas over highly stable nickel-magnesium solid solution catalysts." Fuel Processing Technology 87, no. 5 (2006): 421-428. https://doi.org/10.1016/j.fuproc.2005.10.006 
[25] Wang, Chenguang, Tiejun Wang, Longlong Ma, Yan Gao, and Chuangzhi Wu. "Steam reforming of biomass raw fuel gas over NiO-MgO solid solution cordierite monolith catalyst." Energy Conversion and Management 51, no. 3 (2010): 446-451. https://doi.org/10.1016/j.enconman.2009.10.006 